\title{
Modelling and analysis of a liquid-cooled system for thermal management application of an electronic equipment
}

\author{
Lapo Cheli ${ }^{1, *}$, and Carlo Carcasci ${ }^{1}$ \\ ${ }^{1}$ Department of Industrial Engineering, University of Florence, Via Santa Marta 3, Florence, 50139, \\ Italy
}

\begin{abstract}
The removal of heat from electronic components, increasingly miniaturized with high power dissipation per unit volume, is a significant industrial problem to be resolved, to avoid failures due to excessive temperatures and besides to maintain performance and operating conditions. This article describes the development of a one-dimensional thermodynamic model to simulate the cooling of electronic chips belonging to inverters for stationary PV solar arrays; these are typically located in very different environments, including deserts or very hot areas, so the operating life of theirs inverter units are strongly affected by changes in external environmental conditions. Results have shown that the model allows, with very low calculation times, to quantify the effects of cooling performance and thermal load of electronics both in design and off-design conditions: the working temperature of the components was monitored as the effectiveness of the main heat exchanger vary with the exposure to the external environment over time, in terms of fouling and as the ambient air temperature changes; in this case a simple control system was simulated to limit the maximum temperature of the chips and the air flow rate of the fans. The thermal performances of two types of glycol-based refrigerant fluids have been compared.
\end{abstract}

\section{Introduction}

Recent developments regarding electronic components and other semiconductor devices in terms of miniaturization have led to a huge increase in power density; this trend has created new technological challenges to maintain the reliability of these systems, in particular through limiting the maximum temperature of the chip junction through removing the heat produced by the power dissipation of the devices themselves; in fact, more than $50 \%$ of all electronics failures are caused by shortcomings in temperature control [1]. Some studies have estimated that an average heat flux per unit area of about $150-180 \mathrm{~W} / \mathrm{cm} 2$ was a trustworthy magnitude for a generic electronic component up to 2018 [2].

The fundamental importance of studying the applications of thermal management of electronic equipment has been recognized since the end of the last century: for example,

\footnotetext{
* Corresponding author: lapo.cheli@unifi.it
} 
Nakayama has presented a review of these techniques [3], and Bar-Cohen focuses on both air and liquid cooling techniques of the chips [4].

The main technologies for thermal control of electronic devices are classified between traditional techniques, which use air or liquid systems and advanced ones, such as thermoelectric or nanofluid systems technologies [1], [2], [5]; among the already mature technologies, liquid cooling is certainly very performing, as reported by [6], in particular when compared with air cooling systems, whether with natural or forced convection, which are simpler and cheaper, but less effective in terms of heat quantity to be removed per area.

Among the main industrial applications concerning cooling systems for electronic components, such as data centers, supercomputers and many others [7]-[10], we will focus on inverters; these devices have achieved at this point very high efficiencies, around $98 \%$, and can be easily managed thermally by air convention for residential applications [11]; however, when the electrical power involved is very high, considerable amounts of heat remain to be removed and therefore liquid cooling systems can be considered, as in the case inverters for stationary applications in large photovoltaic solar fields [12]. These systems, often installed in hot and desert areas, can be affected by outside air temperatures even above $50^{\circ} \mathrm{C}$ and so it is essential to maintain reliability over time, controlling the maximum temperatures of the semiconductors mainly for two reasons: on one hand to maintain a constant power supply and avoid sudden disconnection from the grid and on the other hand to minimize maintenance and repair costs [13], which can be higher for stand-alone plants.

Starting from these issues, this work presents the modeling of a tool for the simulation of the thermal control system of inverters for photovoltaic fields [12]: specifically, a detailed model of the cooling plate of the chips and the entire system composed of air-water exchangers has been realized; once the model has been set up to the nominal conditions, analyses were carried out when the ambient air temperature and the fouling of the external exchanger change.

\section{A case study: Inverter Unit}

The schematic layout of the analyzed plant is presented in figure 1(a): the system is composed of: one centrifugal pump (P) that elaborates the refrigerant fluid, specifically a $50 \%$ waterglycol mixture (with propylene or ethylene glycol), two water collectors (WCs), which convey the liquid into the various exchangers, two Cold Plates (CPs), on which the electronic components are mounted and cooled by internal coils of water and two internal air-water heat exchangers (IHEs), whose purpose is to limit the case internal air maximum temperature; the accumulated heat by the refrigerant is rejected in ambient air thanks to an External Heat Exchanger (EHE), which cools the liquid by pumping ambient air through a fan and returns it to the pump inlet temperature. All heat exchangers are air-water countercurrent type.

The key element of the cooling system is the Cold Plate unit, in which the main heat removal and the major thermal gradients take place, due to the presence of semiconductors that dissipate power; figure 1(b) clarifies the arrangement of the IGBT (Insulated Gate Bipolar Transistors) type modules on the surface of the cold plate: the coolant flow inside the cold plate runs into a coil in three branches that initially comes into contact with the modules mounted on the top, i.e. the 6 ones on the top side and the 4 ones on the bottom side, then reverses the direction in an intermediate channel, not in close contact with IGBTs, afterwards returns towards the modules in the lower row ( 3 modules on the top side of the Cold Plate), and finally exits the cold plate. For each module or pair of modules is assigned an identification number of the area where they are mounted: elements from 2 to 5 on the bottom side require the removal of the nominal amount of heat, while modules from 1 to 6 and from 7 to 9 on the top side dissipate half and three-quarters of the nominal value, respectively. 
In design conditions, the main operating parameters of the considered system are listed in Table 1:

Table 1 . Design operating conditions

\begin{tabular}{|c|c|c|}
\hline Name & Symbol & Value [Unit] \\
\hline Total refrigerant flow rate & $\dot{Q}_{w g}$ & $501 / \mathrm{s}$ \\
\hline EHE maximum air flow rate & $\dot{Q}_{E H E, \text { air }}$ & $10000 \mathrm{~m}^{3} / \mathrm{h}$ \\
\hline External air Temperature & $T_{a m b}$ & $50{ }^{\circ} \mathrm{C}$ \\
\hline External air Humidity & $U R_{a m b}$ & $60 \%$ \\
\hline External air Pressure & $P_{a m b}$ & $1.01 \mathrm{bar}$ \\
\hline Glycol in the water-mixture & $\mathrm{PG}, \mathrm{EG}$ & $50 \%$ \\
\hline
\end{tabular}

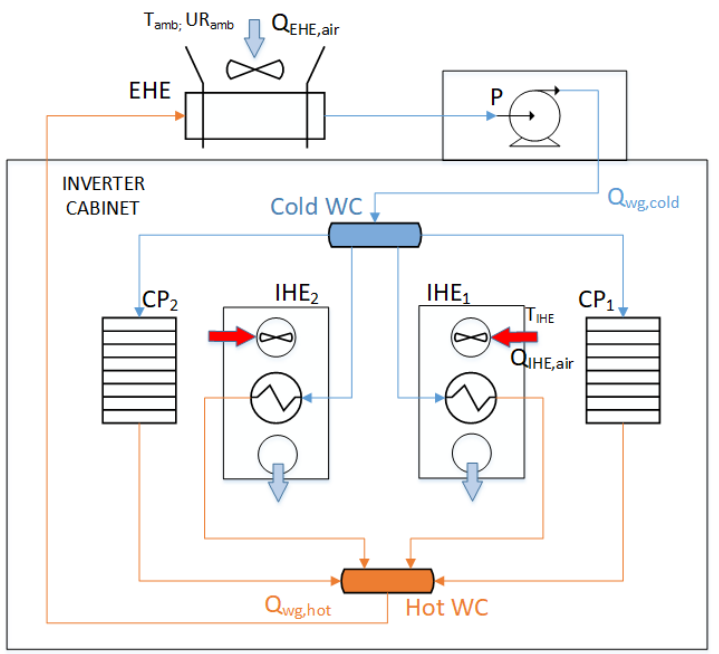

(a)

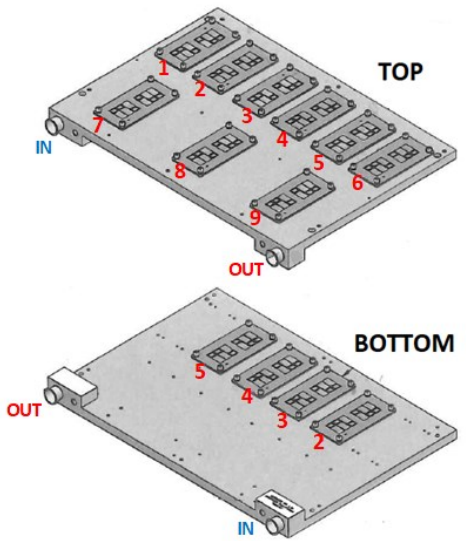

(b)

Fig. 1. Inverter cooling system layout (a) with related Cold Plates modules arrangement scheme (b).

\section{Thermodynamic model}

This chapter describes the thermodynamic model developed for the application previously presented: the program first resolves completely the system by imposing design conditions and then calculates the off-design configuration from the off-design inputs and geometry information provided by the design run.

\subsection{Heat exchangers model}

The liquid-air heat exchangers are modelled with mono dimensional thermodynamic equations and for each of these the mass and energy balances of the water-glycol and air flows are solved. For the generic heat exchanger, the heat flux is given by equation (1):

$$
W_{H E, i}=\dot{m}_{w g, i} c p_{w g} \Delta T_{H E, w g, i}=\dot{m}_{a i r, i} c p_{a i r} \Delta T_{H E, a i r, i}
$$

For the off-design run, the global heat exchange coefficient UA [W/K] is calculated at the end of the design analysis and subsequently used for the off-design calculation, as reported in the following equation: 


$$
\dot{W}=U A \Delta T_{m l}
$$

where is $\Delta T_{m l}$ is the mean logarithmic temperature between the two streams exchanging heat.

\subsection{Cold Plate model}

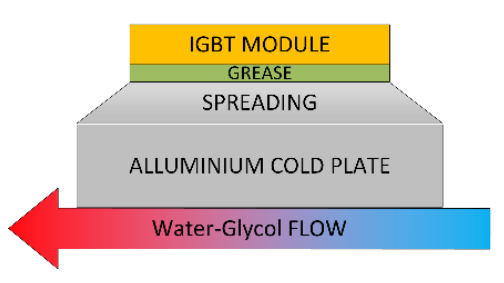

(a)
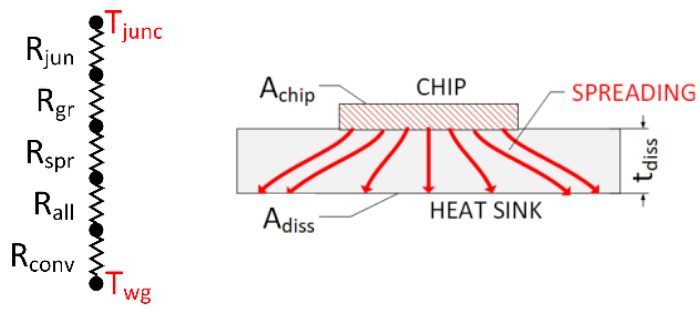

(b)

Fig. 2. Cold Plate simplified cross section scheme and relative thermal resistances for each element (a) and schematic heat flux thermal spreading (b).

The cold plate is the element for the indirect liquid cooling of the electronic modules [5], since between the flow of liquid circulating in the internal coil and the chips are interposed the aluminum of the cold plate itself and any adhesive paste necessary for electrical insulation, frequently called "grease"; therefore the problem will be to obtain the final temperature of the junction, considering all the thermal resistances between the refrigerant and the various layers interposed between the water-glycol and the IGBTs, as schematically shown in figure 2(a).

The main problem is the calculation of the thermal resistance spread for the determination of the overall thermal performance when heat flows from one region to another with different areas, as we can see from figure 2(b), which is commonly seen in power electronics [14][16]. The total thermal resistance $\mathrm{R}_{\text {tot }}[\mathrm{K} / \mathrm{W}]$, on which the actual heat exchange will depend, is obtained by summing the other resistances and its value is given by the following equation,

$$
R_{\text {tot }}=R_{\text {jun }}+R_{g r}+R_{\text {all }}+R_{\text {spr }}+R_{\text {conv }}
$$

where: $R_{\text {jun }}$ is referred to the module with its junction, $R_{\mathrm{gr}}$ refers to the insulating paste, $\mathrm{R}_{\text {all }}$ incorporates the cold plate material thermal properties, $R_{\text {spr }}$ takes into account the spreading effect and $\mathrm{R}_{\text {conv }}$ depends on the convective heat exchange coefficient of the refrigerant flow.

The first three mentioned above are given by the manufacturer, while the last two are calculated. The spreading thermal resistance is obtained through the equation (4), as described by [17] and [18]:

$$
R_{\text {spreading }}=\frac{\Psi_{\max }}{k r_{e q} \sqrt{\pi}}
$$

where $\mathrm{k}$ is the thermal conductivity $[\mathrm{W} / \mathrm{Km}]$ and $\Psi_{\max }$ is calculated by means of the following equation, knowing the ratio between the equivalent radii of the heat sink and the chip (6), the ratio between heatsink thickness and heatsink equivalent radius (7) and $\phi$, calculated through (8), which contains the Biot number (9) and the $\lambda_{c}$ coefficient (10).

$$
\Psi_{\text {max }}=\frac{\varepsilon \tau}{\sqrt{\pi}}+\frac{1}{\sqrt{\pi}}(1-\varepsilon) \phi
$$




$$
\begin{gathered}
\varepsilon=\frac{r_{\text {chip }}}{r_{\text {diss }}} \\
\tau=\frac{t_{\text {diss }}}{r_{\text {diss }}} \\
\phi=\frac{\tanh \left(\lambda_{c} \tau\right)+\frac{\lambda_{c}}{B i}}{1+\left(\frac{\lambda_{c}}{B i}\right) \tanh \left(\lambda_{c} \tau\right)} \\
B i=\frac{h_{\text {diss }} r_{\text {diss }}}{k} \\
\lambda_{c}=\pi+\frac{1}{\sqrt{\pi} \varepsilon}
\end{gathered}
$$

The convective resistance of the fluid is also calculated by the tool, as shown in the next equation, where $A_{\text {diss }}\left[\mathrm{m}^{2}\right]$ is the total dissipator area and $h_{\text {conv }}\left[\mathrm{W} / \mathrm{m}^{2} \mathrm{~K}\right]$ the convective coefficient.

$$
R_{\text {conv }}=\frac{1}{A_{\text {diss }} h_{\text {conv }}}
$$

The convective coefficient $h_{\text {conv, wg }}$ of glycolic water is estimated from Nusselt's dimensionless number $\mathrm{Nu}$; it depends also on the flow regime and is obtained from the following equations:

$$
\begin{gathered}
N u=\frac{48}{11}=4.36 \quad \text { (Laminar flows) } \\
N u=0.023 \operatorname{Re}^{0.8} \operatorname{Pr}^{1 / 3} \quad \text { (Turbulent flows) }
\end{gathered}
$$

For laminar flows (typically for $\operatorname{Re}<2300$ ), the Nusselt number is assumed as a constant value, while instead for turbulent flows in tube we use the equation (13), called the Colburn equation [5]. To improve the overall heat exchange coefficient, inside the coil there are finned channels with rectangular passage sections, so the convective heat exchange coefficient is increased by adding the equivalent heat transfer coefficient of the fin effect (14) to the fluid one,

$$
\begin{gathered}
\eta_{\text {conv }, e q}=\frac{\tanh \left(\sqrt{\varepsilon_{f i n}} L_{f i n n}\right)}{\sqrt{\varepsilon_{f i n}}\left(\frac{A}{P e}\right)} \\
\varepsilon_{f i n}=\frac{\left(h_{\text {conv } P e)}\right.}{k A}
\end{gathered}
$$

where $\mathrm{Pe}[\mathrm{m}]$ is the fin base perimeter, $\mathrm{L}_{\text {finn }}[\mathrm{m}]$ the fin length and $\mathrm{A}\left[\mathrm{m}^{2}\right]$ is the fin base area. Finally, the total value of the finned convective coefficient is obtained:

$$
h_{\text {conv,finn }}=h_{\text {conv,wg }} \eta_{c o n v, e q}
$$

The total convective resistance, anticipated by the simple equation (11), is thus modified:

$$
R_{\text {conv }}=\frac{1}{N_{c h}\left(h_{c o n v, f i n} A_{f i n}+h_{c o n v, H 2 O} L_{c h} L_{I D}\right)}
$$

Where $\mathrm{N}_{\mathrm{ch}}$ is the number of channels, $\mathrm{L}_{\mathrm{ch}}[\mathrm{m}]$ is the length of channel and $\mathrm{L}_{I D}[\mathrm{~m}]$ is the ID module area width, the $\mathrm{A}_{\text {fin }}\left[\mathrm{m}^{2}\right]$ is the area of competence of the fins block, all related to each ID - region of the modules (or pair of them). Once $\mathrm{R}_{\text {tot }}$ is calculated, it is possible to go 
back to the temperature of the junction, knowing that of the water $T_{w g}$ entering the particular control volume, identified by the ID number of figure 1(b), and the module dissipated power $\dot{W}_{\text {mod }}$ inverting equation (18).

$$
\frac{\left(T_{j u n c}-T_{w g}\right)}{\dot{W}_{\text {mod }}}=R_{\text {tot }}
$$

\subsection{Pump and fan model}

While the pump in the program mainly uses the dimensionless operation maps given by the manufacturer directly, from which head, power and efficiency are obtained, this one and the fan can also be modelled for the determination of the electrical power required as follows:

$$
\dot{W}_{e l}=\frac{\dot{m}_{f l} \Delta P}{\rho_{f l} \eta_{m e c} \eta_{e l}}
$$

where $\dot{m}_{f l}[\mathrm{~kg} / \mathrm{s}]$, the air or water mass flow rate and the pressure drop $\Delta P[\mathrm{~Pa}]$ are divided by the mean density $\rho_{f l}\left[\mathrm{~kg} / \mathrm{m}^{3}\right]$ and the mechanical $\eta_{m e c}$ and electrical $\eta_{e l}$ effectiveness.

\subsection{Off-Design strategy}

The off-design model receives the data from the design run: the Pinch Point temperature differences $\Delta \mathrm{T}_{\mathrm{PP} \text {,des, }}$, the flow rates $\mathrm{Q}_{\text {des }}$ and the heat exchangers geometry details $\mathrm{UA}_{\text {des, }}$, then the last inputs are given by the choice of the off-design variables: the external air temperature

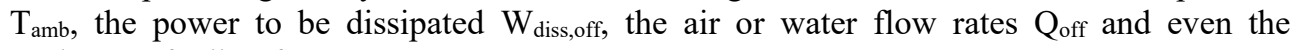
exchanger fouling factor FF.

The tool will resolve the external component (EHE) by recalculating the outlet temperature $\mathrm{T}_{\mathrm{wg}}$ and the processed air flow rate by varying the pinch point, through a fixed UA iterative cycle; therefore all the other system components will be re-simulated and the outputs updated, obtaining, among others, the new temperatures of the modules or the mass flow rates required by the internal exchangers; the model logic flowchart is presented in figure 3 .

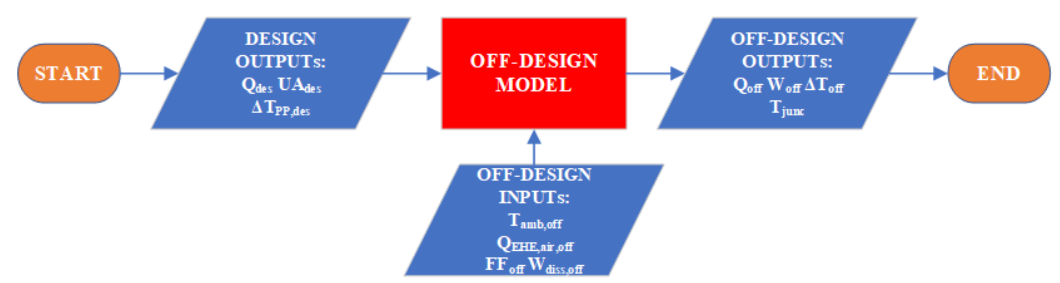

Fig. 3. Off-Design strategy flowchart.

\section{Results}

In this section the results of the design runs, starting from Table 1 data, and of the off-design simulations will be presented. All the simulations were accomplished imposing the pump running at constant speed; moreover, preliminary simulation results found values of the Reynolds number close to transition from laminar to turbulent flow regime, and because this is not exactly calculable and also because of the many internal cold plate machining processes, a completely turbulent regime has been assumed and the program forced to always use the equation (13). 
The calculation time required by the CPU was estimated: with the design inputs, only a maximum of $0.031 \mathrm{~s}$ were required, while $0.422 \mathrm{~s}$ were requested by the program for the longer simulation, processing the complete design and off-design run.

\subsection{Design}

Table 2 shows the results of the plant design simulations for the main components:

Table 2. Results of the plant design simulation

\begin{tabular}{|c|c|c|c|c|c|}
\hline Component & $\mathbf{W}_{\text {des }}[\mathbf{k W}]$ & $\mathbf{Q}_{\text {air,des }}\left[\mathbf{m}^{\mathbf{3}} / \mathbf{h}\right]$ & $\Delta \mathbf{T}_{\mathbf{w g}}\left[{ }^{\circ} \mathbf{C}\right]$ & $\Delta \mathbf{T}_{\text {air }}\left[{ }^{\circ} \mathbf{C}\right]$ & $\Delta \mathbf{T}_{\mathbf{P P}}\left[{ }^{\circ} \mathbf{C}\right]$ \\
\hline IHEi & 4.3 & 1886.512 & 5.228 & 8.000 & 5 \\
\hline $\mathrm{EHE}$ & 23.4 & 9800 & 7.105 & 7.860 & 10 \\
\hline $\mathrm{CPi}$ & 7.4 & - & 8.979 & - & - \\
\hline
\end{tabular}

The results are compared with the current technical limitations of IGBT modules, for which typically a temperature limit of $150^{\circ} \mathrm{C}$ is considered; however, many manufacturers identify a lower value, approximately of $125^{\circ} \mathrm{C}$, to ensure the reliability of the component over time.

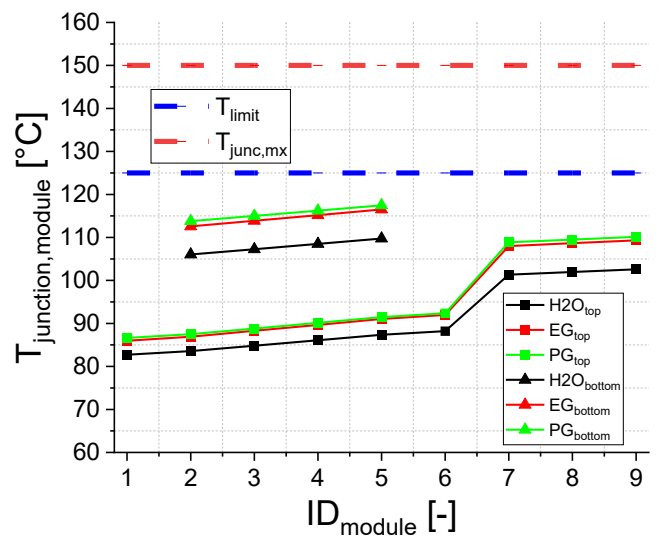

Fig. 4. Chip temperature for each module area.

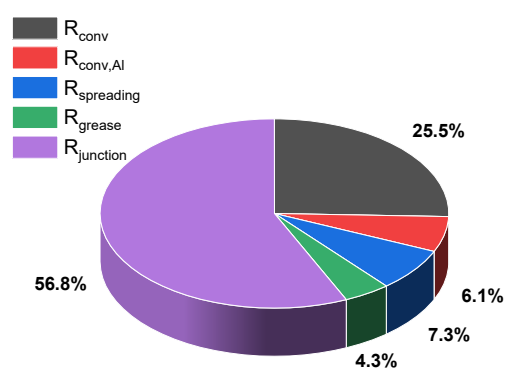

Fig. 5 Thermal resistances impacts on $\mathrm{R}_{\text {tot. }}$

In figure 4 the temperature trends of the junctions of the modules on the top and bottom side are shown: three lines can be seen for each fluid, representing the linear increase in module temperature due to the increase in temperature of the water that received heat from the previous component for each block of IGBTs of the same power. The temperature rise between $6^{\text {th }}$ and $7^{\text {th }}$ module for the top face is due to the higher power dissipated by the last three modules, compared to the first six. The module that reaches the highest temperature is the $5^{\text {th }}$ on the bottom side, with a value of almost $120^{\circ} \mathrm{C}$ for $\mathrm{T}_{\text {junc }}$ using water-based refrigerant and $50 \% \mathrm{PG}$; in fact it is the module that comes into contact with the hottest water among the modules that dissipate the maximum power.

The study of the effect of each layer of the cold plate on the overall thermal resistance allows to understand which are the less efficient zones in the removal of the thermal load of the junction: in figure 5, the percentage values of each single resistance compared to the total resistance are shown: it can be seen how the junction and convection offer the biggest obstacle to the thermal flow; while the first cannot be possible to decrease because it is a data of chip, the second can be improved varying the internal channel configuration of cold plate. 


\subsection{Off-Design}

\subsubsection{Ambient temperature variation and control system simulation}

The maximum temperature of the junctions was tracked as the temperature of the external air change from $5^{\circ} \mathrm{C}$ to $65^{\circ} \mathrm{C}$, which represents the cold well of the plant and therefore the thermodynamic limit; as shown in figure 6 , the $\mathrm{T}_{\text {junc,max }}$ grows approximately linearly with $\mathrm{T}_{\mathrm{amb}}$ as a result of the temperature increase of glycol entering the cold plates and arriving from the external heat exchanger (EHE) which is processing a warmer air flow rate, maintaining all other parameters under design conditions; moreover, the most disadvantageous fluid was seen to be water mixed with Propylene-Glycol at 50\%.

Figure 6 and 7 also shows the results of the simulation of a simple control system: if the maximum temperature of $125^{\circ} \mathrm{C}$ is exceeded by the most thermally stressed module, the system reduces the electric power and consequently the maximum power to be dissipated, this occurs for example at $58^{\circ} \mathrm{C}$ for PG-mixture; the derating effect will be less severe in the case of EG-mixture, which has heat capacity characteristics closer to pure water than the propylene one [19]. In the case of $100 \%$ water, the limit temperature is never reached and therefore the derating has not started.

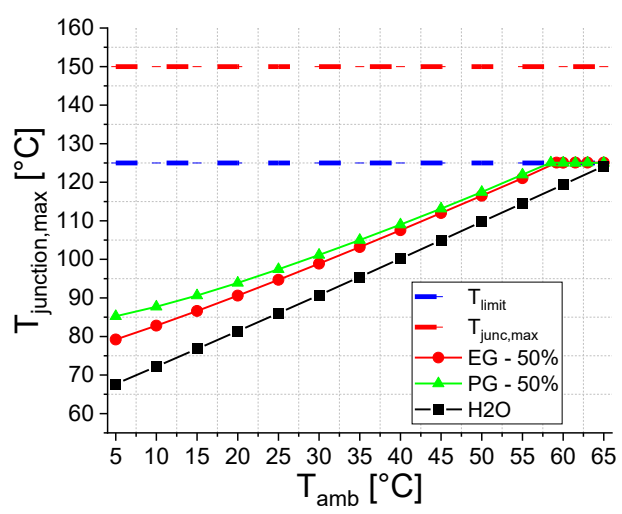

Fig. 6. Junction maximum temperature vs ambient air temperature.

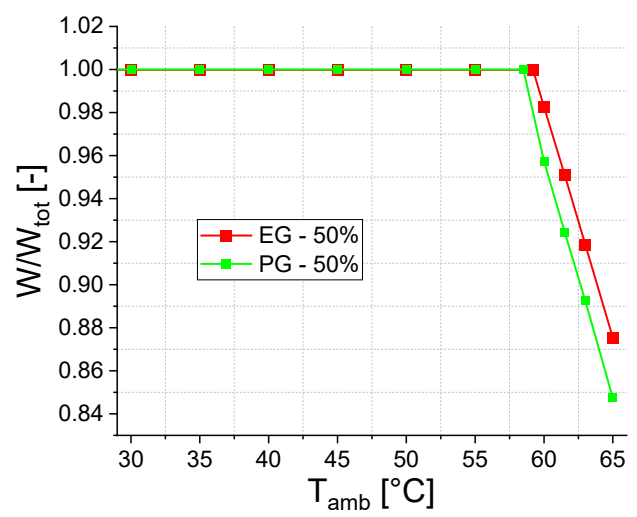

Fig. 7. Cold plate power derating vs ambient air temperature.

Starting from an outside temperature of $10^{\circ} \mathrm{C}$ and considering the PG mixture, the required air mass flow rate of the internal heat exchanger increases with the outside temperature and this is shown in figure 8: the rise of the external air temperature, combined with 3 different fixed maximum temperatures allowed for the internal air, leads to an exponential increase of the required air mass flow rate due to the reduction of the thermal gradient available to the air at equal heat exchange, with an asymptotic limit for the entire system of an ambient temperature between $44.5^{\circ} \mathrm{C}$ and $59.5^{\circ} \mathrm{C}$ for the internal air temperature values set between $65^{\circ} \mathrm{C}$ and $80^{\circ} \mathrm{C}$.

The control systems is also activated for a maximum intern air flow rate of about 0.772 $\mathrm{kg} / \mathrm{s}$ and it reduces the thermal power processed by the IHEs indirectly, that is limiting the power of the modules: for all three cases, to reach $\mathrm{T}_{\mathrm{amb}}$ up to $4.5^{\circ} \mathrm{C}$ more, figure 9 shows that the required derating leads to a reduction in the power of the components up to $20 \%$ of the nominal value, because at fixed flow rate and $\mathrm{T}_{\text {air,IHE,max }}$ the air temperature rise is drastically reduced and consequently the power allowed. Comparing figure 7 and 9 , with a set internal air temperature of $65^{\circ} \mathrm{C}$ or $73^{\circ} \mathrm{C}$ the constraint on the IHE flow rate would be stricter, conversely, with an internal air temperature set at $80^{\circ} \mathrm{C}$, the power derating would be at 
$59.5^{\circ} \mathrm{C}$ and therefore the most stringent bond becomes the maximum temperature of module, exceeded regardless of the inverter cabinet internal temperature and at $58^{\circ} \mathrm{C}$ value of $\mathrm{T}_{\mathrm{amb}}$.

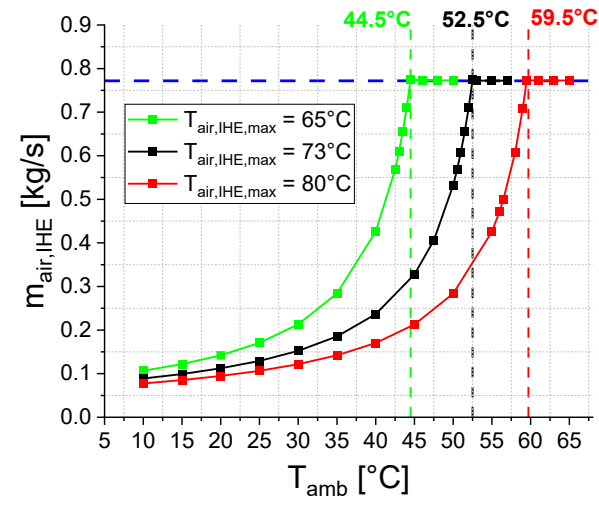

Fig. 8. IHE air mass flow rate vs ambient air temperature.

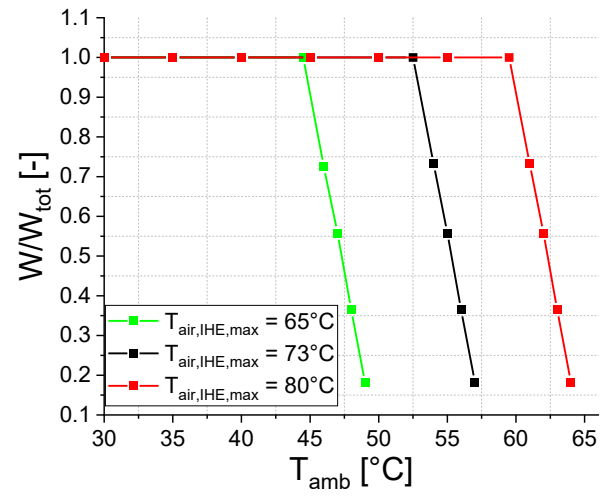

Fig.9. IHE power derating vs ambient air temperature.

\subsubsection{EHE fouling analysis}

The external heat exchanger is investigated more deeply in this section, as its fouling varies; in fact, it is in direct contact with the desert environments where the solar fields are often installed and is therefore the component most subject to deterioration.

In figure 10 the maximum junction temperature of the modules increases according to a progressive percentage reduction of the global heat exchange coefficient of the EHE, due to an increase of the fouling over time, modelled with a correction coefficient FF, of unit value in the case of design and which decreases with increasing fouling effect: for PG mixture, a reduction of around $45 \%$ of the EHE heat exchange coefficient, that is a fouling factor limit value equal to 0.55 , would cause the maximum temperature to reach the assumed lower limits of $125^{\circ} \mathrm{C}$. With the EG mixture the same effect will occur with a lower FF, equal to 0.5.

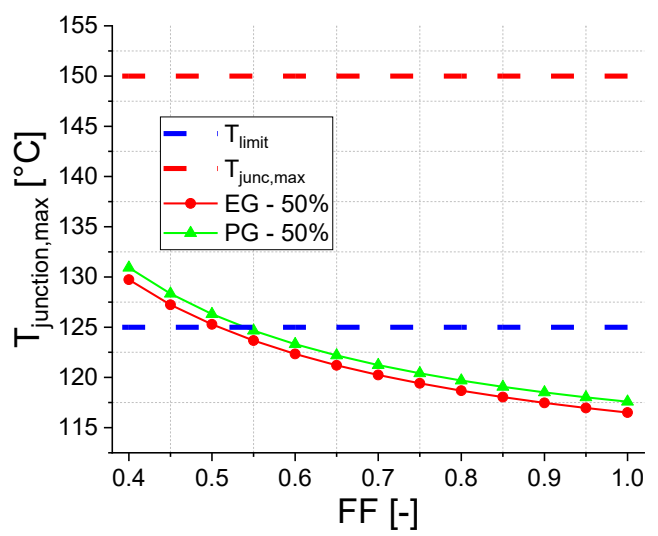

Fig. 10. Junction maximum temperature vs EHE fouling factor.

\section{Conclusions}

A numerical model for the simulation of a cooling system for electronic components for photovoltaic inverters application has been presented; the plant has been studied with one- 
dimensional thermodynamic equations for all the components; moreover, the cold plate for removing heat from chips has been modelled in detail.

After analyzing and setting up the system with design simulation, the main off-design constraints have been studied: a control system application was simulated, imposing the maximum temperature of the junctions on the cold plates not to be exceeded or a limit on the flow rate of the internal fans, through a progressive reduction of the dissipated power, as the temperature of the external air changes; moreover, some sensitivity analyses were carried out to see how the performance of the external heat exchanger varies, considering its fouling.

With at most calculation times around half a second, all the simulations have identified in the 5th of the upper side and pattern module the most at-risk component and how the deterioration of thermal performance is more marked with propylene mixture compared to the same percentage of water and ethylene mixture.

\section{References}

1. L.-T. Yeh and R.C. Chu, Thermal Management of Microelectronic Equipment:Heat Transfer Theory, Analysis Methods and Design Practices (ASME Press, New York, 2002).

2. S.M. Sohel Murshed and C.A. Nieto de Castro, Renewable and Sustainable Energy Reviews 78, 821 (2017).

3. W. Nakayama, Applied Mechanics Reviews 39, 1847 (1986).

4. A. Bar-Cohen, IEEE Transactions on Components, Hybrids, and Manufacturing Technology 10, 159 (1987).

5. Y.A. Cengel, Heat Transfer - A Pratical Approach, 2nd Edition (2002).

6. H.Y. Zhang, D. Pinjala, and Poi-Siong Teo, in Proceedings of the 5th Electronics Packaging Technology Conference (EPTC 2003) (IEEE, Singapore, 2003), pp. 620625.

7. A. Ristow, M. Begovic, A. Pregelj, and A. Rohatgi, IEEE Trans. Ind. Electron. 55, 2581 (2008).

8. A. Capozzoli and G. Primiceri, Energy Procedia 83, 484 (2015).

9. A. Habibi Khalaj and S.K. Halgamuge, Applied Energy 205, 1165 (2017).

10. A. Heydari, in Heat Transfer: Volume 4 (ASMEDC, San Francisco, California, USA, 2005), pp. 877-884.

11. G. Lefevre, N. Degrenne, and S. Mollov, in 2014 16th European Conference on Power Electronics and Applications (IEEE, Lappeenranta, Finland, 2014), pp. 1-10.

12. Product Flyer for ULTRA-TL-OUTD ABB Solar Inverters, (2017).

13. Garron.K. Morris, M.G. Phillips, L. Wei, and R.A. Lukaszewski, in 2016 Annual Reliability and Maintainability Symposium (RAMS) (IEEE, Tucson, AZ, USA, 2016), pp. 1-7.

14. D. Guan, M. Marz, and J. Liang, IEEE Trans. Compon., Packag. Manufact. Technol. 2, 278 (2012).

15. K.-S. Yang, C.-H. Chung, C.-W. Tu, C.-C. Wong, T.-Y. Yang, and M.-T. Lee, Applied Thermal Engineering 70, 361 (2014).

16. B. Vermeersch and G. De Mey, Microelectronics Reliability 48, 734 (2008).

17. S. Song and K.P. Moran, ASME/JSME Thermal Engineering Conference 4, 8 (1995).

18. S. Song, S. Lee, and V. Au, Closed-Form Equation for Thermal Constriction/Spreading Resistance with Variable Resistance Boundary Condition (International Electronics Packaging Society, Wheaton, Ill, 1994), pp. 111-121.

19. D. Bohne, S. Fischer, and E. Obermeier, Berichte Der Bunsengesellschaft Für Physikalische Chemie 88, 739 (1984). 